\title{
$\beta$-Blocker Doses and Heart Rate in Patients with Heart Failure: Results from the National Norwegian Heart Failure Registry
}

\author{
Torfinn Eriksen-Volnes ${ }^{a, b} \quad$ Arne Westheim $^{c} \quad$ Lars Gullestad $^{d-f}$ \\ Eva Kjøl Slind ${ }^{\mathrm{a}}$ Morten Grundtvig ${ }^{\mathrm{a}} \mathrm{g}$ \\ a Department of Medicine and Healthcare, St. Olavs Hospital, Trondheim University Hospital, \\ Trondheim, Norway; ${ }^{b}$ Norwegian University of Science and Technology (NTNU), Trondheim,

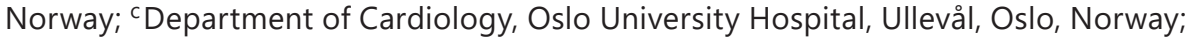 \\ ${ }^{d}$ K.G. Jebsen Centre for Cardiac Research and Centre for Heart Failure Research, Oslo \\ University Hospital, Oslo, Norway; ${ }^{e}$ Division of Cardiovascular and Pulmonary Diseases,

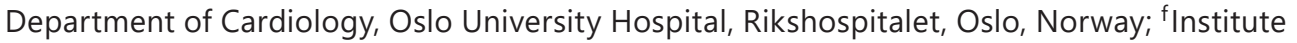 \\ of Clinical Medicine, University of Oslo, Oslo, Norway; ${ }^{9}$ Lillehammer Division, Department \\ of Medicine, Innlandet Hospital Trust, Lillehammer, Norway
}

\section{What Is It about?}

We studied the relationship between the dose of $\beta$-blocker, the heart rate (HR), and the outcome in patients with chronic heart failure and sinus rhythm at stable follow-up in the Norwegian Heart Failure Registry. HR $\geq 70$ beats/min (bpm) was associated with a higher mortality. A high proportion of the patients with a resting $\mathrm{HR} \geq 70 \mathrm{bpm}$ was not treated with or did not tolerate the target dose of $\beta$-blocker. There is probably room for improvement with respect to further reduction of the HR.

\section{Keywords}

Chronic heart failure $\cdot$ Heart rate $\cdot \beta$-Blocker $\cdot$ Comorbidity $\cdot$ Mortality

\section{Abstract}

Background: Use of $\beta$-blockers and titration to the highest tolerated dose are highly recommended by the European Society of Cardiology (ESC) guidelines for treatment of chronic heart failure (HF) with a reduced ejection fraction (HFrEF), but little attention has been paid to the achieved heart rate $(H R)$ during this treatment. Objectives: The aim of the present study was to examine the achieved HR in relation to the use of $\beta$-blockers in these patients. Methods: All of the patients $(n=2,689)$ in the National Norwegian Heart Failure Registry as 
part of the Norwegian Cardiovascular Disease Registry with a sinus rhythm and left ventricular ejection fraction (LVEF) $<40 \%$ at stable follow-up visiting specialised hospital outpatient $\mathrm{HF}$ clinics in Norway were included. The $\beta$-blocker doses were calculated as a percent of the target dose according to ESC HF guidelines. Differences between baseline variables according to the achieved HR were analysed by the Student's $t$ test for continuous variables and Pearson's $\chi^{2}$ test for categorical variables. Linear regression was used to determine the predictors of $H R \geq 70$ beats/min (bpm) in the multivariate analysis. Results: One third of the patients had a resting $\mathrm{HR} \geq 70 \mathrm{bpm}$. Of the patients with an $\mathrm{HR} \geq 70 \mathrm{bpm}, 72.3 \%$ used less than the target dose of $\beta$-blocker; they were younger and had a higher NYHA class, more diabetes mellitus and chronic obstructive pulmonary disease (COPD), and higher $\mathrm{N}$-terminal pro$\mathrm{B}$ type natriuretic peptide (NT-proBNP) levels and estimated glomerular filtration rates compared to the patients with an $\mathrm{HR}<70 \mathrm{bpm}$. The 1-year mortality was 3.1, 3.7, 5.8, and $9.1 \%$ among the patients with an $\mathrm{HR}<70,70-79,80-89$, and $>89$ bpm, respectively. Only 2 patients used ivabradine. Conclusions: In patients with HFrEF and sinus rhythm, an HR $\geq 70$ bpm was associated with worse clinical variables and outcomes. A high proportion of the patients who had an $\mathrm{HR} \geq 70 \mathrm{bpm}$ was not treated with or/did not tolerate the target dose of a $\beta$-blocker, although the $\beta$-blocker dose was higher than in patients with an $\mathrm{HR}<70 \mathrm{bpm}$. This may suggest that increased efforts should be made to further increase the $\beta$-blocker dose, and treatment with ivabradine could be considered among patients with an $H R \geq 70$ bpm.

\section{Introduction}

$\beta$-Blockers are one of the cornerstones in the treatment of patients with chronic heart failure (HF) and a reduced left ventricular ejection fraction (HFrEF). Trials with $\beta$-blockers have documented consistent effects on morbidity and mortality [1-3], and treatment with the target dose or the maximum tolerable dose of $\beta$-blockers as used in clinical trials is recommended in both European Society of Cardiology (ESC) and American HF guidelines [4, 5]. However, data from registries and randomised trials have demonstrated that a large portion of patients do not reach the target dose for $\beta$-blockers or the heart rate (HR) recommended in the guidelines [6].

The relationship between an elevated HR and mortality in patients with chronic HF is well recognised [7-11]. The HF-Action trial showed that a higher $\beta$-blocker dose rather than a reduced HR was associated with improved outcomes, while data from the COMET (Carvedilol or Metoprolol European Trial) showed that both the achieved $\beta$-blocker dose and HR were independently associated with outcomes $[12,13]$. However, 2 meta-analysis demonstrated that only the magnitude of the HR reduction and not the achieved $\beta$-blocker dose was associated with all-cause mortality $[14,15]$. On the other hand, a study of reverse left ventricular remodelling with carvedilol and the MERIT-HF (Metoprolol CR/XL Randomized Intervention Trial in Congestive Heart Failure) have not confirmed this relationship [16, 17]. There is inconclusive evidence regarding other drugs that also lower HR (digoxin and amiodarone), while nondihydropyridine calcium blockers are known to cause harm [18]. Thus, it is still undecided whether the effect of $\beta$-blockers reflects a positive physiological effect or a causal inference of the HR or whether the HR alone is a risk marker that reflects the burden of the underlying disease. The aim of this observational study from the National Norwegian Heart Failure Registry (NNHFR) was to determine the outcome in relation to HR and the dosage of $\beta$-blocker in a real-life chronic HF population with sinus rhythm and a left ventricular ejection fraction (LVEF) $<40 \%$. 


\section{Methods}

\section{Patient Selection}

Chronic HF outpatients with sinus rhythm and an LVEF $<40 \%$ referred to $39 \mathrm{HF}$ clinics in Norwegian hospitals between 2014 and 2018 were included. The patients were enrolled successively after being diagnosed with chronic HF of any aetiology according to the previous and latest ESC HF guidelines [4, 19]. All of the participating hospitals have specially trained nurses working in close cooperation with cardiologists. Patient data were registered at 3 visits in the NNHFR, i.e., at the first registered visit at the HF clinic, after individual optimisation of HF treatment at stable follow-up, and finally 6 months after stable follow-up. The NNHFR is a web-based system, and data entered into the system were demographic data, aetiology of HF, LVEF, use of medications including dose of $\beta$-blockers, actual HR, and blood pressure. All data pertinent to this study were registered at the stable follow-up visit, except for measurements of LVEF, background comorbidities, and smoking history, which was recorded at the first visit, and mortality, which was recorded at the actual time of the event. HR was recorded from the ECG. The doses of $\beta$-blockers given to the patients were calculated as a percent of the target dose according to the guidelines [4]. Mortality data were obtained continuously from the Norwegian national registry and automatically recorded in the NNHFR. Missing values in the registry were none for medications, comorbidities, LVEF, age, and sex and less than $2 \%$ for other variables. No patients were lost to follow-up with regard to mortality.

\section{Statistical Analysis}

Continuous variables were expressed as means \pm SD and categorical variables as frequencies (\%). Differences in continuous variables were compared using Student's $t$ test and differences in categorical variables were compared using Pearson's $\chi^{2}$ test. The 2-tailed significance level was set at $p<0.05$. The population was divided into 2 groups according to HR, i.e., $\geq 70$ and $<70 \mathrm{bpm}$. $\mathrm{HR} \geq 70 \mathrm{bpm}$ is the threshold for further attempts to lower the HR according to the latest ESC guidelines [4]. Renal function was expressed as the estimated glomerular filtration rate (eGFR) and calculated using the Chronic Kidney Disease Epidemiology Collaboration (CKD-EPI) equation [20]. Linear regression was used to enter variables that were significantly different in univariate analyses (Table 1) to determine independent variables to explain predictors for having an $\mathrm{HR} \geq 70 \mathrm{bpm}$.

Survival curves were presented using Kaplan-Meier statistics according to the patient's HR. All statistical analyses were performed using IBM SPSS Statistics version 25 (IBM SPSS Statistics, USA).

\section{Results}

\section{Characteristics of the Study Cohort}

Altogether 2,689 patients with HFrEF and sinus rhythm were registered in the NNHFR at stable follow-up. These patients had NYHA I, II, III, and IV $(13.3,54.8,30.5$, and $1.2 \%$, respectively) at the first visit to the HF clinic. The average NYHA class was II at the first visit. At the last follow up visits between 2014 and 2018 patients had NYHA I, II, III, and IV (i.e., 28.8, 56.7, 13.8 , and $0.7 \%$ respectively). The average NYHA class was 1.8 for patients with an HR $\leq 70$ bpm and 2.0 for patients with an HR $\geq 70 \mathrm{bpm}$.

At stable follow-up, 95.3\% of the patients received a $\beta$-blocker, $91.7 \%$ received an angiotensin-converting enzyme inhibitor (ACE-I) or an angiotensin receptor blocker (ARB) in combination with a $\beta$-blocker, and $38.6 \%$ received a mineralocorticoid receptor antagonist (MRA). Two patients received ivabradine (i.e., 1 in each group). 
Table 1. Characteristics of the patients with sinus rhythm and an LVEF $<40 \%$ dichotomised at a heart rate of $70 \mathrm{bpm}$

\begin{tabular}{|c|c|c|c|}
\hline Variable & $\begin{array}{l}\mathrm{HR}<70 \mathrm{bpm} \\
(n=1,814)\end{array}$ & $\begin{array}{l}\mathrm{HR} \geq 70 \mathrm{bpm} \\
(n=875)\end{array}$ & $p$ value \\
\hline Age, years & $67.2 \pm 11.7$ & $64.3 \pm 12.9$ & $<0.001$ \\
\hline Female sex & 26.4 & 28.3 & ns \\
\hline BMI & $27.1 \pm 5.2$ & $27.8 \pm 5.9$ & ns \\
\hline Current smoker & 19.0 & 24.7 & $<0.001$ \\
\hline \multicolumn{4}{|l|}{$\begin{array}{l}\text { Medical history } \\
\text { Ischemic heart disease }\end{array}$} \\
\hline as the main cause of HF & 52.6 & 51.5 & ns \\
\hline Diabetes mellitus & 19.8 & 33.7 & $<0.001$ \\
\hline COPD or asthma & 16.0 & 21.9 & 0.001 \\
\hline Cancer & 5.0 & 6.6 & ns \\
\hline Stroke & 9.3 & 8.3 & ns \\
\hline \multicolumn{4}{|l|}{ Cardiac parameters } \\
\hline Systolic BP, mm Hg & $124.8 \pm 19.5$ & $122.0 \pm 19.1$ & $<0.001$ \\
\hline LVEF, \% & $28.6 \pm 6.5$ & $28.0 \pm 6.4$ & ns \\
\hline NYHA class & $1.8+0.6$ & $2.0+0.7$ & $<0.001$ \\
\hline \multicolumn{4}{|l|}{ Laboratory values } \\
\hline Anaemia & 21.3 & 25.8 & 0.010 \\
\hline Serum sodium, mmol/L & $140.2 \pm 2.9$ & $139.6 \pm 3.2$ & $<0.001$ \\
\hline Serum potassium, mmol/L & $4.50 \pm 0.43$ & $4.49 \pm 0.44$ & ns \\
\hline NT-proBNP, pg/mL & $845(347-1,949)$ & $926(355-2,541)$ & $<0.001$ \\
\hline $\mathrm{BNP}, \mathrm{pg} / \mathrm{mL}$ & $197(78-412)$ & $138(62-372)$ & ns \\
\hline $\mathrm{eGFR}, \mathrm{mL} / \mathrm{min} / 1.73 \mathrm{~m}^{2}$ & $66.7 \pm 22.6$ & $70.2 \pm 24.7$ & $<0.001$ \\
\hline \multicolumn{4}{|l|}{ Medication } \\
\hline Use of $\beta$-blocker & 95.9 & 94.5 & ns \\
\hline$\beta$-Blocker dose, $\%$ & $49.3 \pm 31.2$ & $57.8 \pm 33.6$ & $<0.001$ \\
\hline Use of ACE-I/ARB & 96.0 & 94.2 & ns \\
\hline Use of MRA & 38.7 & 38.4 & ns \\
\hline Diuretic dose ${ }^{\mathrm{a}}, \mathrm{mg}$ & $27.2 \pm 44.2$ & $34.7 \pm 43.0$ & $<0.001$ \\
\hline \multicolumn{4}{|l|}{ Device } \\
\hline CRT & 3.6 & 3.5 & ns \\
\hline ICD & 14.4 & 10.4 & 0.002 \\
\hline
\end{tabular}

The total number of patients was 2,689. Values are expressed as percent, means \pm SD, or medians (percentiles 25-75) for each group with $p$ values for differences. BP, blood pressure; NYHA, New York Heart Association; CRT, cardiac resynchronization therapy; ICD, implanted cardioverter defibrillator. ${ }^{\text {a }}$ The daily dose was calculated as furosemide $40 \mathrm{mg}$ = bumetanide $1 \mathrm{mg}$ and thiazide $10 \mathrm{mg}$ was added.

The demographic and clinical characteristics of the patients with a resting HR $<70$ and $\geq 70 \mathrm{bpm}$ are given in Table 1 . The univariate analysis demonstrated that patients with an HR $\geq 70$ bpm were younger; more had diabetes mellitus and COPD, they had a higher NYHA functional class and higher eGFR and NT-proBNP levels and lower levels of serum sodium, and they were more were anaemic. While the use of $\beta$-blockers was similar between the 2 groups, the doses of these agents were higher in patients with an $\mathrm{HR} \geq 70 \mathrm{bpm}$. The dose of diuretics was also higher. There were no differences in LVEF, BMI, or the dose of ACE-I/ARB and MRA between the patients with an $\mathrm{HR}<70$ and $\mathrm{HR} \geq 70 \mathrm{bpm}$. More patients with diabetes mellitus used a $\beta$-blocker $(p=0.03)$ and in higher doses compared to patients without diabetes mellitus $(p<0.001)$. Patients with COPD or asthma were treated with a $\beta$-blocker in $96.2 \%$ of the patients compared to $95.8 \%$ in other patients $(p=0.82)$, but they used higher doses $(p=0.05)$. 


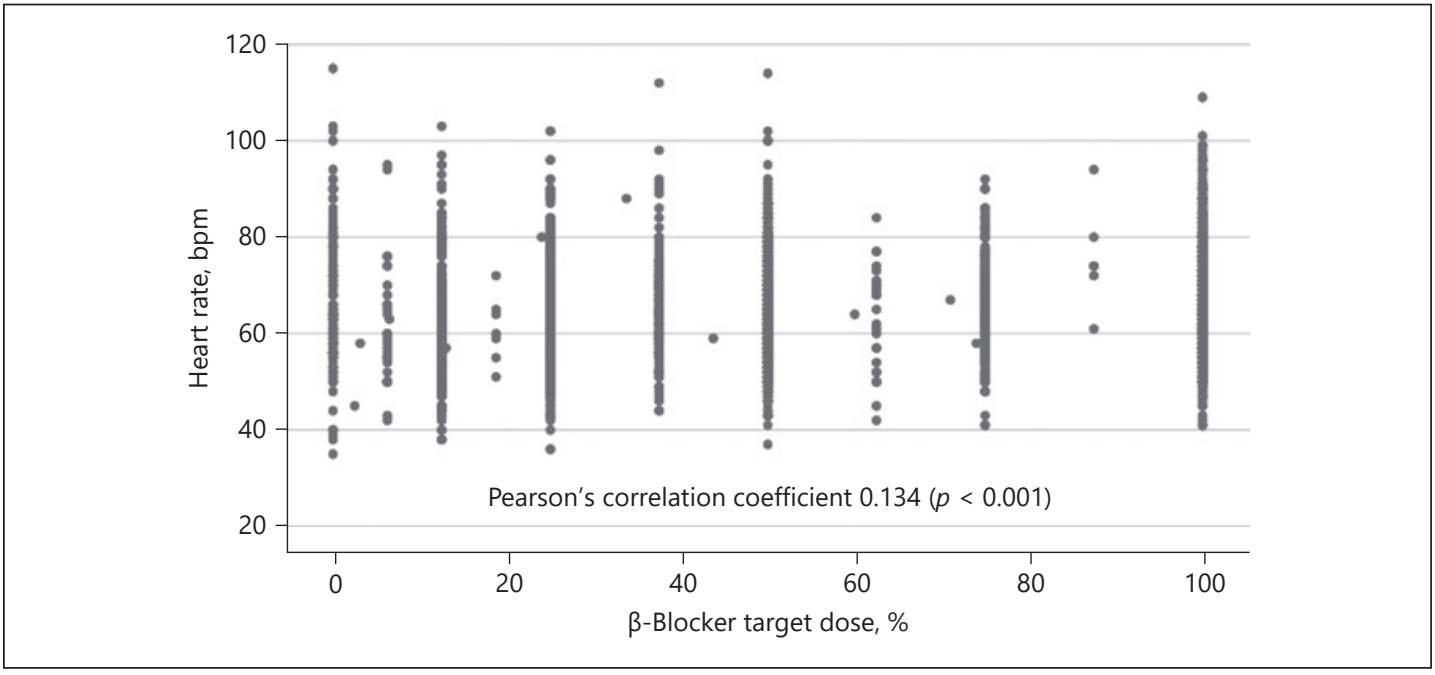

Fig. 1. Scatter diagram of HR (bpm) in relation to the $\beta$-blocker target dose (\%) in patients with sinus rhythm and an LVEF $<40 \%$ at stable follow-up $(n=2,689)$. $\beta$-Blocker dose, $\%$ of the target dose according to the guidelines [4].

Table 2. Percent target doses of $\beta$-blocker versus number (\%) of patients within the heart rate groups

\begin{tabular}{|c|c|c|c|c|c|}
\hline \multirow[t]{2}{*}{ Heart rate } & \multicolumn{4}{|c|}{$\beta$-Blocker target dose } & \multirow{2}{*}{$\begin{array}{l}\text { Total } \\
\text { number } \\
(N=2,689)\end{array}$} \\
\hline & $0-24 \%$ & $25-49 \%$ & $50-99 \%$ & $\geq 100 \%$ & \\
\hline$<70 \mathrm{bpm}$ & $293(16.2)$ & $500(27.6)$ & $659(36.3)$ & $362(20.0)$ & 1,814 \\
\hline 70-79 bpm & $56(9.8)$ & $138(24.1)$ & $206(36.0)$ & $172(30.1)$ & 572 \\
\hline 80-89 bpm & 31 (13.7) & 39 (17.3) & $80(35.4)$ & $45(31.0)$ & 226 \\
\hline$>89 \mathrm{bpm}$ & $22(28.6)$ & $14(18.2)$ & $16(20.8)$ & $25(32.5)$ & 77 \\
\hline
\end{tabular}

$\beta$-Blocker target dose: \% of target dose according to the guidelines [4]. Values represent the number of patients (percent).

\section{Achieved HR in Relation to Doses of $\beta$-Blocker}

Of the third of the patients who had an HR $\geq 70 \mathrm{bpm}$, the mean dose of $\beta$-blockers in this group was higher than in the patients with an $\mathrm{HR}<70 \mathrm{bpm}$. There was a very weak correlation between the dose of $\beta$-blockers and the achieved HR (Fig. 1). A description of the achieved HR in relation to $\beta$-blocker doses is shown in Table 2. Of those with the highest HR, 46.8 and $28.6 \%$ used less than 50 and $100 \%$ of the target doses, respectively (Table 2).

\section{Predictors of a High HR}

Linear regression showed that patients with diabetes mellitus, COPD or asthma, a higher NYHA functional class, a lower blood pressure, higher natriuretic peptide levels, a higher eGFR, lower serum sodium levels, and higher doses of $\beta$-blocker were significant predictors of an HR $\geq 70 \mathrm{bpm}$ (Table 3).

\section{Outcome in Relation to HR}

The outcome was significantly worse in the patients with an HR $\geq 70 \mathrm{bpm}$ compared to the patients with an $\mathrm{HR}<70 \mathrm{bpm}(p=0.028)$ (Fig. 2). The 1-year mortality rates after stable follow-up for the 2,689 patients were $3.1,3.7,5.8$, and 9.1\%, respectively, among the patients 
Table 3. Multivariable linear regression of variables for the relation to $\mathrm{HR} \geq 70 \mathrm{bpm}$

\begin{tabular}{|c|c|c|c|c|c|c|c|}
\hline \multirow[t]{2}{*}{ Variable } & \multirow[t]{2}{*}{$B$} & \multirow[t]{2}{*}{ SE } & \multirow[t]{2}{*}{$\beta$} & \multirow[t]{2}{*}{$t$} & \multicolumn{2}{|l|}{$95 \%$ CI } & \multirow[t]{2}{*}{$p$ value } \\
\hline & & & & & lower limit & upper limit & \\
\hline Constant & 1.379 & 0.442 & & 3.123 & 0.513 & 2.245 & 0.002 \\
\hline Age (years) & -0.004 & 0.001 & -0.102 & -4.130 & -0.006 & -0.002 & $<0.001$ \\
\hline DM (0 and 1$)$ & 0.144 & 0.021 & 0.132 & 6.730 & 0.102 & 0.186 & $<0.001$ \\
\hline COPD/asthma (0 and 1) & 0.068 & 0.024 & 0.056 & 2.879 & 0.022 & 0.114 & 0.004 \\
\hline $\mathrm{BP}(\mathrm{mm} \mathrm{Hg})$ & -0.001 & 0.000 & -0.040 & -2.052 & -0.002 & 0.000 & 0.040 \\
\hline NYHA (1-4) & 0.077 & 0.015 & 0.108 & 5.244 & 0.048 & 0.105 & $<0.001$ \\
\hline Serum sodium, mmol/L & -0.008 & 0.003 & -0.049 & -2.507 & -0.014 & -0.002 & 0.012 \\
\hline Four tiles of peptides $(1-4)^{a}$ & 0.023 & 0.009 & 0.054 & 2.507 & 0.005 & 0.040 & 0.012 \\
\hline $\mathrm{eGFR}\left(\mathrm{mL} / \mathrm{min} / 1.73 \mathrm{~m}^{2}\right)$ & 0.001 & 0.000 & 0.069 & 2.836 & 0.000 & 0.002 & 0.005 \\
\hline$\beta$-Blocker dose $\mathrm{b}^{\mathrm{b}}$ & 0.001 & 0.000 & 0.084 & 4.258 & 0.001 & 0.002 & $<0.001$ \\
\hline
\end{tabular}

DM, diabetes mellitus; BP, blood pressure; NYHA, New York Heart Association. ${ }^{\text {a }}$ Combined N-terminal pro-B-type natriuretic peptide and BNP-type natriuretic peptide. ${ }^{b}$ Percent of the target dose according to the guidelines [4].

Fig. 2. Kaplan-Meier plot of survival of patients with an LVEF $<40 \%$ from the time of stable follow-up when attending specialised outpatient HF hospital clinics. $n=1,814$ for $\mathrm{HR}<70 \mathrm{bpm}$ and $n=875$ for $\mathrm{HR} \geq 70 \mathrm{bpm}$.

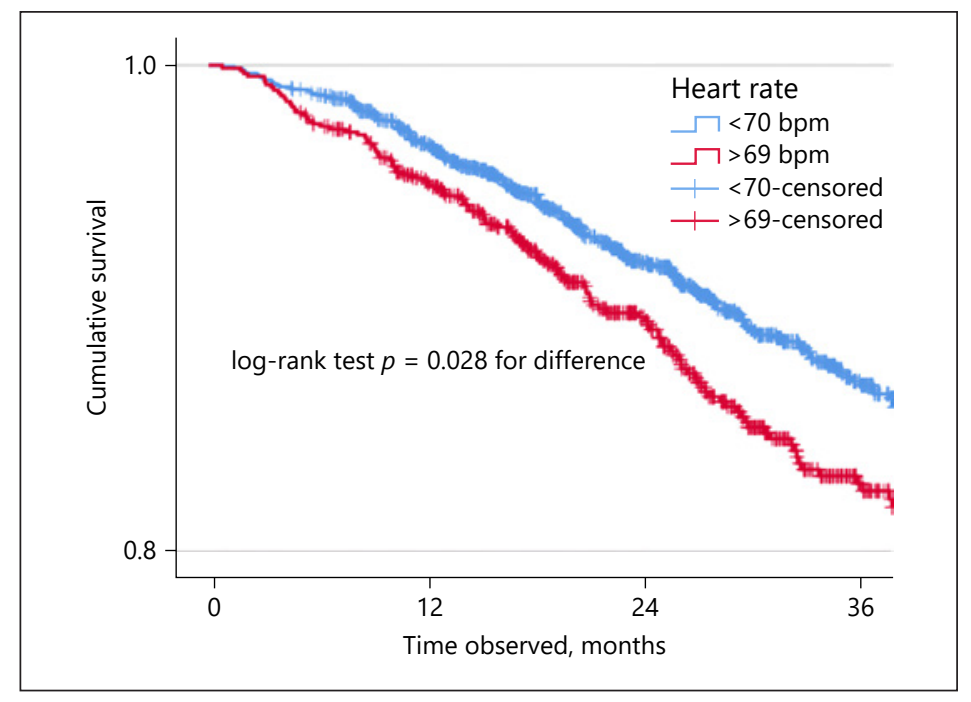

with an HR $<70,70-79,80-89$, and $>89 \mathrm{bpm}$. A small proportion (4.5\%) of the patients who did not use a $\beta$-blocker had a 1-year a mortality rate of $7.3 \%$. Only 2 of the patients without $\beta$-blockade and an $\mathrm{HR}<70 \mathrm{bpm}$ died $(2.7 \%)$ in this period.

\section{Discussion}

The major finding of the present study was that one third of the patients with chronic $\mathrm{HFrEF}$ and sinus rhythm had a resting HR $\geq 70 \mathrm{bpm}$ despite attendance at HF outpatient clinics for optimal titration of the $\beta$-blocker dose. Although the use of $\beta$-blockers was high, the dose was suboptimal, with close to half of the patients using less than $50 \%$ of the target dose. The mortality was significantly higher in the patients with an HR $\geq 70 \mathrm{bpm}$ compared to the patients with an HR $<70 \mathrm{bpm}$. 
A high proportion of patients with an HFrEF in sinus rhythm in the NNHFR had a resting HR $\geq 70 \mathrm{bmp}$. The higher mortality in this group is in accordance with previous trials $[7,21]$ and confers additional action set by recent HF guidelines [4].

Our study demonstrated a very weak correlation between the $\beta$-blocker dose and the achieved HR. We have no data to confirm a high adherence rate that is thought to be the case in our patients. However, from previous trials we know that the number of $\beta$-receptors and the sensitivity of these receptors declines with the degree of HF [22] and given that the group with the highest $\mathrm{HR}$ also had a more severe HF, as judged from the higher NT-proBNP and NYHA class, we believe that the most important factor is related to a different physiologic response.

The patients with an HR $\geq 70 \mathrm{bpm}$ registered a higher dose of $\beta$-blockers compared to the patients with an $\mathrm{HR}<70 \mathrm{bpm}$. We suggest the finding of higher doses of $\beta$-blocker in patients with a higher HR to be logical as more ill patients will have a higher HR and will require higher doses. We therefore think that this reflects a true up-titration of the $\beta$-blocker dose in patients who need it most. The question is whether the dose could have been up-titrated even further in these patients who are thought to have a high adrenergic drive. Thus, for more severe HF, the higher $\beta$-blocker dose is needed, as well as support of a more individualised approach considering both the dosing of $\beta$-blockers as well as the achieved HR.

In the MERIT trial the mean dose of metoprolol CR/XL was $159 \mathrm{mg} /$ day $(79.5 \%$ of the target dose) and $87 \%$ reached the target dose of $200 \mathrm{mg} /$ day. The most common reasons for not achieving the target dose were a low HR and low blood pressure [17]. In the present study, patients with an HR $\geq 70 \mathrm{bpm}$ had a relatively preserved blood pressure and this is probably not the reason why patients were adequately up-titrated. An important lesson from the MERIT trial was that, given a serious attempt to increase the dosing of metoprolol CR/XL, its effect was independent of the baseline HR [17], supporting an increase in the $\beta$-blocker dose as the first step in care.

Only 2 patients in our study received ivabradine. This study is important to highlight the use of ivabradine in the treatment of HFrEF. The registry has the policy to very strongly advise following the class IA recommendation according to the ESC 2016 guidelines for HF [4]. The guidelines states that the use of ivabradine should be considered in patients with an LVEF $<40 \%$ with a IIa evidence class B recommendation. The HR-lowering effect of ivabradine in HF was investigated in the BEAUTIFUL and SHIFT trials [23, 24]. While the BEAUTIFUL trial showed neutral results regarding the primary end point, the SHIFT trial demonstrated a reduction in cardiovascular death and HF hospitalisations of $18 \%$ in patients with an HFrEF in sinus rhythm and an HR of at least $70 \mathrm{bpm}$, an effect largely driven by an effect on HF hospitalisations [23]. Based on this, the use of ivabradine was included in the ESC guidelines in 2012 but only lately in the ACC/AHA guidelines [5], where it was given a IIa recommendation to reduce HF hospitalisations in symptomatic (NYHA class II-III) patients with HFrEF who are receiving optimal medical treatment including the maximum tolerated dose of $\beta$-blocker. Although most of the patients $(\sim 90 \%)$ in the SHIFT trial were taking a beta-blocker only $26 \%$ of the patients were taking the target dose. Thus, the conservative recommendation in the US guidelines, suboptimal dosing of $\beta$-blockers that are consider cornerstone in the treatment in $\mathrm{HF}$, and an effect primarily on $\mathrm{HF}$ hospitalisations and not on CV mortality might be contributing factors to the low use of ivabradine. A low use of this drug has also been observed in newer randomised HF trials like the DAPA-HF $[25,26]$, where $5 \%$ received ivabradine and in the CHAMP-HF registry where $1 \%$ received ivabradine, suggesting that this therapy is generally low in use [26].

The proportions of the patients in the NYHA functional status groups at stable follow-up compare very well with patients in the recent DAPA-HF study [26].

Some subgroups might be considered in need of special attention. Obstructive pulmonary disease was more frequent in the group of patients with an $\mathrm{HR} \geq 70 \mathrm{bpm}$. Patients with COPD who attended an HF outpatient clinic were less frequently treated with a $\beta$-blocker compared 
to patients without COPD [27], but this was not the case in our study where patients used higher doses than patients without obstructive pulmonary disease. A meta-analysis showed that $\beta_{1}$ selective blockers are safe for the treatment of patients with a reactive airway disease including COPD [28]. Another interesting comorbidity is diabetes mellitus. A meta-analysis has shown that a large majority ( $>90 \%)$ of patients with diabetes mellitus and a reduced LVEF used a $\beta$-blocker [29]. That is the case in this study, where patients with diabetes mellitus used even higher doses than patients without diabetes mellitus, and it was also shown in a previous study from the older Norwegian HF registry [30]. It is therefore certain that the patients with obstructive pulmonary disease (COPD/asthma) and diabetes mellitus in our study contributed to a large extent to the high number of patients with a high HR and that these patients used on average a higher $\beta$-blocker dose than the patients with an $\mathrm{HR}<70 \mathrm{bpm}$.

The mean dose of $\beta$-blocker in our study was suboptimal, suggesting room for improvement in the dose as the first step, but patients treated at the target or maximum tolerated dose of $\beta$-blocker and a resting $\mathrm{HR} \geq 70 \mathrm{bpm}$ should have been considered for treatment with ivabradine.

In summary, our study that included patients with chronic HF with sinus rhythm and LVEF $<40 \%$ showed that a high HR was associated with worse outcomes. A high proportion of the patients with a resting $\mathrm{HR} \geq 70 \mathrm{bpm}$ was not treated with or did not tolerate the target dose of $\beta$-blocker. Only 2 patients were treated with ivabradine. Thus, increased efforts should be made to further increase the $\beta$-blocker dose in addition to considering the implementation of treatment with ivabradine in outpatients with chronic HF with sinus rhythm, an $\mathrm{LVEF}<40 \%$, and a resting $\mathrm{HR} \geq 70 \mathrm{bpm}$.

\section{Acknowledgement}

The NNHFR is critically reliant on high-quality data from participating outpatient's HF clinics. Thanks to all of the contributors who made this study possible.

\section{Statement of Ethics}

This study is pursuant to the regulations of the Norwegian register of cardiovascular diseases form 2012 §2-2. The National Institute of Public Health is responsible for correct information and shall ensure that the data processed in the registry is correct, relevant, and necessary [31]. This study complies with GDPR.

\section{Disclosure Statement}

The authors have no conflict of interests to declare.

\section{Funding Sources}

This study was done without any financial support.

\section{Author Contributions}

All of the persons listed as authors contributed with data collection and analysis, writing of this article, and revision of previous literature in the field. 


\section{References}

1 CIBIS-II Investigators and Committees. The Cardiac Insufficiency Bisoprolol Study II (CIBIS-II): a randomised trial. Lancet. 1999 Jan;353(9146):9-13.

2 MERIT-HF study group. Effect of metoprolol CR/XL in chronic heart failure: Metoprolol CR/XL Randomised Intervention Trial in Congestive Heart Failure (MERIT-HF). Lancet. 1999 Jun;353(9169):2001-7.

3 Packer M, Fowler MB, Roecker EB, Coats AJ, Katus HA, Krum H, et al.; Carvedilol Prospective Randomized Cumulative Survival (COPERNICUS) Study Group. Effect of carvedilol on the morbidity of patients with severe chronic heart failure: results of the carvedilol prospective randomized cumulative survival (COPERNICUS) study. Circulation. 2002 Oct;106(17):2194-9.

4 Ponikowski P, Voors AA, Anker SD, Bueno H, Cleland JG, Coats AJ, et al.; Authors/Task Force Members; Document Reviewers. 2016 ESC Guidelines for the diagnosis and treatment of acute and chronic heart failure: the Task Force for the diagnosis and treatment of acute and chronic heart failure of the European Society of Cardiology (ESC). Developed with the special contribution of the Heart Failure Association (HFA) of the ESC. Eur J Heart Fail. 2016 Aug;18(8):891-975.

5 Yancy CW, Jessup M, Bozkurt B, Butler J, Casey DE Jr, Colvin MM, et al. 2017 ACC/AHA/HFSA Focused Update of the 2013 ACCF/AHA Guideline for the Management of Heart Failure: A Report of the American College of Cardiology/American Heart Association Task Force on Clinical Practice Guidelines and the Heart Failure Society of America. J Card Fail. 2017 Aug;23(8):628-51.

6 Bhatt AS, DeVore AD, DeWald TA, Swedberg K, Mentz RJ. Achieving a Maximally Tolerated $\beta$-Blocker Dose in Heart Failure Patients: Is There Room for Improvement? J Am Coll Cardiol. 2017 May;69(20):2542-50.

7 Castagno D, Skali H, Takeuchi M, Swedberg K, Yusuf S, Granger CB, et al.; CHARM Investigators. Association of heart rate and outcomes in a broad spectrum of patients with chronic heart failure: results from the CHARM (Candesartan in Heart Failure: Assessment of Reduction in Mortality and morbidity) program. J Am Coll Cardiol. 2012 May; 59(20):1785-95.

8 Habal MV, Liu PP, Austin PC, Ross HJ, Newton GE, Wang X, et al. Association of heart rate at hospital discharge with mortality and hospitalizations in patients with heart failure. Circ Heart Fail. 2014 Jan;7(1):12-20.

9 Fox K, Ford I, Steg PG, Tendera M, Robertson M, Ferrari R; BEAUTIFUL investigators. Heart rate as a prognostic risk factor in patients with coronary artery disease and left-ventricular systolic dysfunction (BEAUTIFUL): a subgroup analysis of a randomised controlled trial. Lancet. 2008 Sep;372(9641):817-21.

10 Fox K, Borer JS, Camm AJ, Danchin N, Ferrari R, Lopez Sendon JL, et al.; Heart Rate Working Group. Resting heart rate in cardiovascular disease. J Am Coll Cardiol. 2007 Aug;50(9):823-30.

11 Böhm M, Swedberg K, Komajda M, Borer JS, Ford I, Dubost-Brama A, et al.; SHIFT Investigators. Heart rate as a risk factor in chronic heart failure (SHIFT): the association between heart rate and outcomes in a randomised placebo-controlled trial. Lancet. 2010 Sep;376(9744):886-94.

12 Fiuzat M, Wojdyla D, Pina I, Adams K, Whellan D, O'Connor CM. Heart Rate or Beta-Blocker Dose? Association With Outcomes in Ambulatory Heart Failure Patients With Systolic Dysfunction: Results From the HF-ACTION Trial. JACC Heart Fail. 2016 Feb;4(2):109-15.

13 Metra M, Torp-Pedersen C, Swedberg K, Cleland JG, Di Lenarda A, Komajda M, et al. Influence of heart rate, blood pressure, and beta-blocker dose on outcome and the differences in outcome between carvedilol and metoprolol tartrate in patients with chronic heart failure: results from the COMET trial. Eur Heart J. 2005 Nov;26(21):2259-68.

14 McAlister FA, Wiebe N, Ezekowitz JA, Leung AA, Armstrong PW. Meta-analysis: beta-blocker dose, heart rate reduction, and death in patients with heart failure. Ann Intern Med. 2009 Jun;150(11):784-94.

15 Flannery G, Gehrig-Mills R, Billah B, Krum H. Analysis of randomized controlled trials on the effect of magnitude of heart rate reduction on clinical outcomes in patients with systolic chronic heart failure receiving betablockers. Am J Cardiol. 2008 Mar;101(6):865-9.

16 Arnold RH, Kotlyar E, Hayward C, Keogh AM, Macdonald PS. Relation between heart rate, heart rhythm, and reverse left ventricular remodelling in response to carvedilol in patients with chronic heart failure: a single centre, observational study. Heart. 2003 Mar;89(3):293-8.

17 Gullestad L, Wikstrand J, Deedwania P, Hjalmarson A, Egstrup K, Elkayam U, et al.; MERIT-HF Study Group. What resting heart rate should one aim for when treating patients with heart failure with a beta-blocker? Experiences from the Metoprolol Controlled Release/Extended Release Randomized Intervention Trial in Chronic Heart Failure (MERIT-HF). J Am Coll Cardiol. 2005 Jan;45(2):252-9.

18 Dobre D, Borer JS, Fox K, Swedberg K, Adams KF, Cleland JG, et al. Heart rate: a prognostic factor and therapeutic target in chronic heart failure. The distinct roles of drugs with heart rate-lowering properties. Eur J Heart Fail. 2014 Jan;16(1):76-85.

19 McMurray JJ, Adamopoulos S, Anker SD, Auricchio A, Böhm M, Dickstein K, et al.; Task Force for the Diagnosis and Treatment of Acute and Chronic Heart Failure 2012 of the European Society of Cardiology; ESC Committee for Practice Guidelines. ESC guidelines for the diagnosis and treatment of acute and chronic heart failure 2012: The Task Force for the Diagnosis and Treatment of Acute and Chronic Heart Failure 2012 of the European Society of Cardiology. Developed in collaboration with the Heart Failure Association (HFA) of the ESC. Eur J Heart Fail. 2012 Aug;14(8):803-69.

20 Levey AS, Stevens LA, Schmid CH, Zhang YL, Castro AF 3rd, Feldman HI, et al.; CKD-EPI (Chronic Kidney Disease Epidemiology Collaboration). A new equation to estimate glomerular filtration rate. Ann Intern Med. 2009 May;150(9):604-12. 
21 McAlister FA, Wiebe N, Ezekowitz JA, Leung AA, Armstrong PW. Meta-analysis: beta-blocker dose, heart rate reduction, and death in patients with heart failure. Ann Intern Med. 2009 Jun;150(11):784-94.

22 Bristow MR, Ginsburg R, Minobe W, Cubicciotti RS, Sageman WS, Lurie K, et al. Decreased catecholamine sensitivity and beta-adrenergic-receptor density in failing human hearts. N Engl J Med. 1982 Jul;307(4):205-11.

23 Swedberg K, Komajda M, Böhm M, Borer JS, Ford I, Dubost-Brama A, et al.; SHIFT Investigators. Ivabradine and outcomes in chronic heart failure (SHIFT): a randomised placebo-controlled study. Lancet. 2010 Sep; 376(9744):875-85.

24 Fox K, Ford I, Steg PG, Tendera M, Ferrari R; BEAUTIFUL Investigators. Ivabradine for patients with stable coronary artery disease and left-ventricular systolic dysfunction (BEAUTIFUL): a randomised, double-blind, placebo-controlled trial. Lancet. 2008 Sep;372(9641):807-16.

25 McMurray JJ, Solomon SD, Inzucchi SE, Køber L, Kosiborod MN, Martinez FA, et al.; DAPA-HF Trial Committees and Investigators. Dapagliflozin in patients with heart failure and reduced ejection fraction. N Engl J Med. 2019 Nov;381(21):1995-2008.

26 McMurray JJ, DeMets DL, Inzucchi SE, Køber L, Kosiborod MN, Langkilde AM, et al.; DAPA-HF Committees and Investigators. The Dapagliflozin And Prevention of Adverse-outcomes in Heart Failure (DAPA-HF) trial: baseline characteristics. Eur J Heart Fail. 2019 Nov;21(11):1402-11.

27 De Blois J, Simard S, Atar D, Agewall S; Norwegian Heart Failure Registry. COPD predicts mortality in HF: the Norwegian Heart Failure Registry. J Card Fail. 2010 Mar;16(3):225-9.

28 Salpeter SR, Ormiston TM, Salpeter EE. Cardioselective beta-blockers in patients with reactive airway disease: a meta-analysis. Ann Intern Med. 2002 Nov;137(9):715-25.

29 Edelmann F, Wachter R, Düngen HD, Störk S, Richter A, Stahrenberg R, et al.; German "Competence Network Heart Failure". Heart failure therapy in diabetic patients-comparison with the recent ESC/EASD guideline. Cardiovasc Diabetol. 2011 Feb;10(1):15.

30 Stubnova V, Os I, Grundtvig M, Waldum-Grevbo B. Prevalent Diabetes Mellitus: Mortality and Management in Norwegian Heart Failure Outpatients. Cardiology. 2016;134(4):413-22.

31 Stortinget. Forskrift om innsamling og behandling av helseopplysninger i Nasjonalt register over hjerte-og karlidelser. Available from: https//lovdata.no/dokument/SF/forskrift/2011-12-16-1250. 